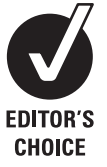

CHOICE

\title{
Rheumatoid arthritis versus diabetes as a risk factor for cardiovascular disease: a cross-sectional study, the CARRÉ Investigation
}

\author{
V P van Halm, ${ }^{1,2} \mathrm{M} \mathrm{J}$ L Peters, ${ }^{1}$ A E Voskuyl, ${ }^{1} \mathrm{M}$ Boers, ${ }^{1,3} \mathrm{~W}$ F Lems, ${ }^{1,2} \mathrm{M}$ Visser, ${ }^{4}$ \\ C D A Stehouwer, ${ }^{4,5}$ A M W Spijkerman, ${ }^{4} \mathrm{~J}$ M Dekker, ${ }^{4}$ G Nijpels, ${ }^{4}$ R J Heine, ${ }^{4,6}$ \\ L M Bouter, ${ }^{4}$ Y M Smulders, ${ }^{7}$ B A C Dijkmans, ${ }^{1,2}$ M T Nurmohamed ${ }^{1,2,7}$
}

${ }^{1}$ Department of Rheumatology, VU University Medical Center, Amsterdam, The Netherlands:

${ }^{2}$ Department of Rheumatology, Jan van Breemen Institute Amsterdam, The Netherlands; ${ }^{3}$ Department of Clinical Epidemiology and Biostatistics, VU University Medical Center, Amsterdam, The Netherlands: ${ }^{4}$ EMGO Institute, VU University Medical Center, Amsterdam, The Netherlands; ${ }^{5}$ Department of Internal Medicine, University Hospital Maastricht, Maastricht, The Netherlands; ${ }^{6}$ Department of Endocrinology, VU University Medical Center, Amsterdam,

The Netherlands; ${ }^{7}$ Department of Internal Medicine, VU University Medical Center, Amsterdam, The Netherlands

Correspondence to: Dr M T Nurmohamed, VU University Medical Center, Departments of Internal Medicine and Rheumatology, P 0 Box 7057, 1007 MB

Amsterdam, The Netherlands; mt.nurmohamed@vumc.nl

VPVH and MJLP contributed equally to this article.

Accepted 3 August 2008

Published Online First

12 August 2008

\section{ABSTRACT}

Objectives: Patients with rheumatoid arthritis (RA) have an increased cardiovascular risk, but the magnitude of this risk is not known precisely. A study was undertaken to investigate the associations between RA and type 2 diabetes (DM2), a well-established cardiovascular risk factor, on the one hand, and cardiovascular disease (CVD) on the other.

Methods: The prevalence of CVD (coronary, cerebral and peripheral arterial disease) was determined in 353 randomly selected outpatients with RA (diagnosed between 1989 and 2001, aged 50-75 years; the CARRÉ study) and in participants of a population-based cohort study on diabetes and CVD (the Hoorn study). Patients with RA with normal fasting glucose levels from the CARRÉ study (RA, $n=294$ ) were compared with individuals from the Hoorn study with normal glucose metabolism (non-diabetic, $n=258$ ) and individuals with DM2 (DM2, $n=194)$.

Results: The prevalence of CVD was 5.0\% (95\% Cl 2.3\% to $7.7 \%)$ in the non-diabetic group, $12.4 \%(95 \% \mathrm{Cl} 7.5 \%$ to $17.3 \%)$ in the DM2 group and $12.9 \%$ (95\% Cl $8.8 \%$ to $17.0 \%$ ) in those with RA. With non-diabetic individuals as the reference category, the age- and gender-adjusted prevalence odds ratio (OR) for CVD was 2.3 (95\% Cl 1.1 to 4.7) for individuals with DM2 and 3.1 (95\% Cl 1.6 to 6.1) for those with RA. There was an attenuation of the prevalences after adjustment for conventional cardiovascular risk factors (OR 2.0 (95\% Cl 0.9 to 4.5) and 2.7 (95\% Cl 1.2 to 5.9), respectively).

Conclusions: The prevalence of CVD in RA is increased to an extent that is at least comparable to that of DM2. This should have implications for primary cardiovascular prevention strategies in RA.

Rheumatoid arthritis (RA) is a chronic inflammatory joint disease of unknown aetiology affecting approximately $1 \%$ of the general population. ${ }^{1}$ The standardised mortality ratios are markedly raised in RA, which seems largely attributable to cardiovascular disease (CVD). ${ }^{2}$

The increased cardiovascular risk in patients with RA could have several causes. First, the prevalence of cardiovascular risk factors such as dyslipidaemia, diabetes, hypertension, higher body mass index, higher waist to hip ratio or impaired physical fitness may be increased. ${ }^{3}$ Second, in chronic diseases such as RA, unrelated conditions such as cardiovascular risk factors are frequently undertreated. ${ }^{4}$ Third, the chronic inflammatory process in RA may increase the risk of CVD. ${ }^{56}$
The purpose of this study is to determine more precisely the magnitude of cardiovascular risk associated with RA. Better knowledge of this risk is relevant for determining optimal primary cardiovascular prevention strategies. A relevant comparator to RA is type 2 diabetes (DM2), which is regarded by many as a CVD risk equivalent, implying that preventive strategies in these patients should be equal to those with established CVD. ${ }^{7}$

\section{METHODS}

\section{The CARRÉ study}

"CARRÉ" is a Dutch acronym for CARdiovascular research and $\mathbf{R h E u m a t o i d ~ a r t h r i t i s . ~ T h e ~ C A R R E ́ ~}$ study is a cohort study investigating CVD and its risk factors in patients with RA who will be followed prospectively for at least 5 years. For the present study the cross-sectional baseline data were used. In 2000, a random sample of patients with RA registered at the Jan van Breemen Institute in Amsterdam, The Netherlands, was drawn. Patients were eligible for participation if they fulfilled the 1987 American College of Rheumatology classification criteria, were diagnosed between 1989 and 2001, and were aged between 50 and 75 years. ${ }^{8}$ Patients were enrolled between January 2001 and January 2002. A total of 353 patients with RA participated. For the present study we excluded patients with known type 1 diabetes $(n=6)$ or patients for whom fasting blood samples were missing $(n=4)$.

\section{The Hoorn study}

The Hoorn study is a Dutch cohort study of glucose metabolism and other cardiovascular risk factors. In 1989 a random sample of all men and women aged $50-75$ years was drawn from the municipal population registry office of Hoorn. A total of 2484 individuals participated giving a response rate of $71 \%$. An extensive cardiovascular investigation was performed in an age-, genderand glucose tolerance-stratified random subsample of 631 participants (response rate 89\%). ${ }^{9}$

\section{RA-related data in the CARRÉ study}

All patients with RA attended the outpatient clinic at the Jan van Breemen Institute, where they were seen by a research physician, and completed a questionnaire recording demographic data, medical and medication history. A physical examination 
was performed, including the 28 joint disease activity index score (DAS-28). ${ }^{10}$ Furthermore, fasting blood samples were taken to measure inflammatory parameters (erythrocyte sedimentation rate (ESR), C-reactive protein (CRP)), serological markers (IgM-rheumatoid factor (IgM-RF), anti-cyclic citrullinated peptides (anti-CCP) antibodies) and (possible) cardiovascular risk factors such as lipid levels. IgM-RF and anti-CCP antibodies were measured using in-house enzyme-linked immunosorbent assays as described previously. ${ }^{11}$ In addition, to assess the functional (disability) status, the Health Assessment Questionnaire (HAO) was used. The HAQ is a generic measure used in various chronic diseases, using a self-reported patientorientated questionnaire. ${ }^{12}$

\section{Assessment of diabetes and CVD in both study protocols}

The diagnosis of diabetes was assessed using the 1999 World Health Organization criteria. ${ }^{13}$ In the Hoorn study, the mean of two oral glucose tolerance tests (OGTTs) and the mean of two fasting plasma glucose levels were used. Cohort participants with a mean fasting plasma glucose level $<6.1 \mathrm{mmol} / 1$ and a mean OGTT $<7.8 \mathrm{mmol} / \mathrm{l}$ were classified as having normal glucose metabolism (non-diabetic, $\mathrm{n}=258$ ) and those with a fasting plasma glucose level $\geqslant 7.0 \mathrm{mmol} / 1$, OGTT $\geqslant 11.1 \mathrm{mmol} /$ 1 , or already treated with glucose-lowering agents were classified as type 2 diabetes (DM2, $\mathrm{n}=194)$. The DM2 group consisted of $76(35 \%)$ individuals who were already being treated with oral antidiabetics or insulin and 127 (65\%) individuals having DM2 based on two OGTTs and two fasting plasma glucose measurements performed at baseline. The mean (SD) HBA1c was $7.1(1.8) \%$ for DM2. ${ }^{14}$

In the CARRÉ study, fasting plasma glucose levels were used and those with glucose levels $<6.1 \mathrm{mmol} / \mathrm{l}$ and not treated with glucose-lowering agents were classified as patients having normal fasting glucose (RA, $\mathrm{n}=294$ ).

In both cohorts CVD ascertainment was done according to similar standard operation procedures and, if there was a positive history of CVD, they qualified only when written information from the participant's general practitioner was obtained. ${ }^{15}$ CVD consisted of coronary, cerebral or peripheral arterial disease. In brief, coronary diseases were defined as a history of myocardial infarction confirmed by a cardiologist or a percutaneous transluminal coronary angioplasty or surgery for ischaemic heart disease. Cerebral arterial disease was defined as a history of a stroke or a transient ischaemic attack confirmed by a neurologist or a carotid endarterectomy. Peripheral arterial disease was defined as peripheral arterial reconstructive surgery, limb amputation or an ankle brachial pressure index (ABPI) $<0.50$. ABPI was obtained with the use of a hand-held Doppler, measuring the maximum systolic pressure of either the dorsalis pedis artery or posterior tibial artery divided by the maximum systolic blood pressure in the brachial artery after a 5 min resting period in a supine position in the CARRÉ study, and by means of Doppler-assisted systolic blood pressure measurement taken from the brachial and the three crural arteries on both sides in the Hoorn study, as previously described. ${ }^{16}$ The lowest ABPI of either limb was used for statistical analyses.

\section{Cardiovascular risk factors in both study protocols}

Cardiovascular risk factors assessed during physical examination were blood pressure, body mass index and waist to hip ratio. Height and weight were measured barefoot wearing light clothes only. The body mass index was calculated as the ratio of weight and squared height. Double readings of the systolic and diastolic blood pressure were obtained on the right arm with the subject in the sitting position after a 5 min rest. Hypertension was defined as a systolic blood pressure $>140 \mathrm{~mm} \mathrm{Hg}$ and/or a diastolic blood pressure of $>90 \mathrm{~mm} \mathrm{Hg}$ and/or the current use of antihypertensive medication. The waist circumference and hip circumference were measured at the level midway between the lowest rib margin and the iliac crest and at the widest level over the greater trochanters, respectively. The mean value of two measurements was used. Measurements in both study protocols were performed by different physicians.

For each patient, fasting blood samples were collected for assessment of glucose, CRP, creatinine and lipid levels. Renal function was assessed using the Cockcroft-Gault formula in $\mathrm{ml} /$ min: $((140-$ age $) \times$ body weight/creatinine $\times 71) \times 0.85$ if female). The formula is given in traditional units; to convert it to International System units $(\mathrm{mg} / \mathrm{dl})$, creatinine is multiplied by 88.4. Serum total cholesterol (TC) and triglyceride levels were analysed by enzymatic techniques. Low-density lipoprotein (LDL) cholesterol levels were calculated by means of the Friedewald formula (except when triglycerides were $>$ $8.0 \mathrm{mmol} / \mathrm{l}$ ) and the TC/HDLc ratio was calculated by dividing total cholesterol levels by high-density lipoprotein (HDL) cholesterol levels. Finally, patients were classified as never, former or current smokers.

\section{Statistical analyses}

Characteristics of the populations of the CARRÉ and Hoorn studies with a normal distribution were presented as means with standard deviations or as absolute numbers with percentages of the total. Non-normally distributed variables were presented as medians with interquartile ranges. Baseline characteristics of the control group were compared with patients with DM2 and RA using the Student $t$ test, MannWhitney $U$ test and Pearson $\chi^{2}$ test, when appropriate.

Prevalence odds ratios (ORs) for CVD were calculated for patients with DM2 and RA relative to non-diabetic controls. Logistic regression analysis was done with three separate models: (1) univariate analyses (model I); (2) age- and genderadjusted analyses (model II); and (3) analyses adjusting for the following cardiovascular risk factors: systolic blood pressure, antihypertensive agents, TC/HDL ratio, lipid-lowering drugs, waist circumference, creatinine and smoking (model III). In order to investigate the influence of inflammation on the risk of CVD, CRP was separately introduced as an independent variable. Analyses were carried out using SPSS 14.0 software and $p$ values $<0.05$ were considered statistically significant.

\section{RESULTS}

\section{Characteristics of patients with RA}

A total of 343 patients with RA were included; 49 had either known diabetes or fasting plasma glucose levels $>6.1 \mathrm{mmol} / \mathrm{l}$ and were therefore excluded, leaving 294 patients with RA with normal fasting glucose levels in the study (table 1). Most of the participants were IgM-RF positive and had erosions on the radiographs. The mean disease duration was $>7$ years and disease activity was moderate with a mean DAS-28 of almost 4.

\section{Cardiovascular diseases}

The prevalence of CVD based on a history of at least one confirmed cardiovascular event was $5.0 \%$ (95\% CI $2.3 \%$ to $7.7 \%)$ in non-diabetic controls, $12.4 \%$ (95\% CI $7.5 \%$ to $17.3 \%)$ in DM2 and $12.9 \%$ (95\% CI $8.8 \%$ to $17.0 \%)$ in patients with RA (table 1 ). 
Table 1 Comparison of RA with DM2 and controls of the Hoorn study

\begin{tabular}{|c|c|c|c|}
\hline \multirow[b]{2}{*}{ Groups } & \multicolumn{2}{|l|}{ Hoorn study } & \multirow{2}{*}{$\begin{array}{l}\text { CARRÉ study } \\
\text { RA }\end{array}$} \\
\hline & Non-diabetic controls & DM2 & \\
\hline Number & 258 & 194 & 294 \\
\hline \multicolumn{4}{|l|}{ Demographic variables } \\
\hline Age (years) & $63(7)$ & $66(7)^{*}$ & $63(7)$ \\
\hline Female $(\%)$ & 49 & 45 & $65^{*}$ \\
\hline Cardiovascular disease, $\mathrm{N}(\%)$ & $13(5.0 \%)$ & $24(12.4 \%)^{*}$ & $38(12.9 \%)^{*}$ \\
\hline Coronary artery disease, $\mathrm{n}(\%)$ & $10(3.9 \%)$ & $11(5.7 \%)$ & $23(7.8) \%^{*}$ \\
\hline Cerebral arterial disease, $\mathrm{n}(\%)$ & $2(0.8 \%)$ & $7(3.6 \%)^{*}$ & $13(4.4 \%)^{*}$ \\
\hline Peripheral arterial disease, $\mathrm{n}(\%)$ & $2(0.8 \%)$ & $10(5.2 \%)^{*}$ & $4(1.4 \%)$ \\
\hline \multicolumn{4}{|l|}{ Cardiovascular risk factors } \\
\hline Systolic blood pressure (mm Hg) & $133(18)$ & $144(19)^{*}$ & $141(20)^{*}$ \\
\hline Diastolic blood pressure $(\mathrm{mm} \mathrm{Hg})$ & $81(10)$ & $83(10)^{*}$ & $81(9)$ \\
\hline Antihypertensive drugs (\%) & 17 & $41^{*}$ & 24 \\
\hline Hypertension (\%) & 38 & $76^{*}$ & $57^{*}$ \\
\hline Creatinine $(\mu \mathrm{mol} / \mathrm{l})$ & $92(15)$ & $92(26)$ & $88(16)^{*}$ \\
\hline Cockroft-Gault (ml/min) & $71(16)$ & $76(18) *$ & $74(19)$ \\
\hline Waist circumference $(\mathrm{cm})$ & $90(10)$ & $99(11)^{*}$ & $92(13)$ \\
\hline Hip circumference $(\mathrm{cm})$ & $101(7)$ & $104(8)^{*}$ & $104(10)^{*}$ \\
\hline Waist:hip ratio & $0.89(0.08)$ & $0.95(0.08)^{*}$ & $0.88(0.08)$ \\
\hline Weight $(\mathrm{kg})$ & $74(11)$ & $80(12)^{*}$ & $75(14)$ \\
\hline Height $(\mathrm{cm})$ & $169(9)$ & $167(9)$ & $168(9)$ \\
\hline BMI $\left(\mathrm{kg} / \mathrm{m}^{2}\right)$ & $26(3)$ & $29(4)^{*}$ & $26(5)$ \\
\hline Total cholesterol (mmol/l) & $6.6(1.2)$ & $6.5(1.3)$ & $5.8(1.1)^{*}$ \\
\hline HDL cholesterol (mmol/l) & $1.4(0.4)$ & $1.1(0.3)^{*}$ & $1.5(0.5)^{*}$ \\
\hline LDL cholesterol (mmol/l) & $4.6(1.0)$ & $4.3(1.1)^{*}$ & $3.7(1.0)^{*}$ \\
\hline Triglycerides $(\mathrm{mmol} / \mathrm{l})$ & $1.5(1.0-1.8)$ & $2.0(1.4-2.8)^{*}$ & $1.3(1.0-1.8)$ \\
\hline Statins $(\%)$ & 1 & 2 & $11^{*}$ \\
\hline \multicolumn{4}{|l|}{ Smoking } \\
\hline Never (\%) & 35 & 39 & $21^{*}$ \\
\hline Former smoker (\%) & 35 & 36 & $47^{*}$ \\
\hline Current smoker (\%) & 30 & 25 & $32^{*}$ \\
\hline $\mathrm{CRP}(\mathrm{mg} / \mathrm{l})$ & $1(1-3)$ & $2(1-4)^{*}$ & $6(3-18)^{*}$ \\
\hline \multicolumn{4}{|l|}{ RA variables } \\
\hline Age at onset RA (years) & & & $55(8)$ \\
\hline RA duration (years) & & & 7 (4-10) \\
\hline IgM-RF $\geqslant 30 \mathrm{IU} / \mathrm{ml}(\%)$ & & & 70 \\
\hline Anti-CCP $\geqslant 50 \mathrm{AU} / \mathrm{ml}(\%)$ & & & 54 \\
\hline Erosions on radiographs (\%) & & & 83 \\
\hline DAS-28 & & & $3.8(1.4)$ \\
\hline $\mathrm{HAO}$ & & & $0.8(0-3)$ \\
\hline Current methotrexate users $(\%)$ & & & 60 \\
\hline Current sulfasalazine users (\%) & & & 15 \\
\hline Current hydroxychloroquine users (\%) & & & 7 \\
\hline Current prednisone users $(\%)$ & & & 15 \\
\hline Current biological users $(\%)$ & & & 10 \\
\hline
\end{tabular}

Data presented as mean (SD), $\mathrm{n}(\%)$ or median (interquartile range).

BMI, body mass index; CCP, cyclic citrullinated peptide; CRP, C-reactive protein; CVD, cardiovascular disease; DAS-28, 28 joint disease activity index score; $\mathrm{DM}$ 2, diabetes mellitus type 2; $\mathrm{HAQ}$, health assessment questionnaire; $\mathrm{HDL}$, high-density lipoprotein; LDL, low-density lipoprotein; RA, rheumatoid arthritis; RF, rheumatoid factor.

*Variables significantly different from non-diabetic controls.

Compared with the non-diabetic controls, cerebral and peripheral arterial disease were more frequently observed in DM2, and coronary and cerebral arterial disease more often in patients with RA.

\section{Cardiovascular risk factors}

Table 1 summarises the cardiovascular risk factors of participants in the Hoorn and CARRÉ studies. Compared with nondiabetic controls, patients with RA were more often female, had a lower mean waist to hip ratio, lower total and LDL cholesterol and higher HDL cholesterol levels. Patients with RA also had higher rates of smoking, hypertension and use of lipid-lowering drugs. No significant differences were observed in serum creatinine levels, renal function, waist circumference, weight and body mass index. CRP levels were higher in patients with RA.

\section{Prevalence of CVD in non-diabetic controls, DM2 and RA}

Compared with non-diabetic controls, the OR for CVD was 3 times higher in the RA group and approximately 2.5 times higher in the DM2 group (models I and II, table 2). Similar to diabetes, adjustment for cardiovascular risk factors (systolic blood pressure, antihypertensive agents, TC/HDL cholesterol, lipid-lowering drugs, waist circumference, creatinine and 
Table 2 Prevalence odds ratios (ORs) for cardiovascular disease using controls as a reference

\begin{tabular}{lll}
\hline & OR (95\% Cl) & p Value \\
\hline Model I & & \\
Non-diabetic controls & 1.00 (reference) & \\
DM2 & $2.62(1.29$ to 5.32$)$ & 0.008 \\
RA & $2.81(1.46$ to 5.42$)$ & 0.002 \\
Model II & 1.00 (reference) & \\
Non-diabetic controls & $2.31(1.13$ to 4.72$)$ & 0.022 \\
DM2 & $3.11(1.59$ to 6.08$)$ & 0.001 \\
RA & & \\
Model III & 1.00 (reference) & \\
Non-diabetic controls & $2.01(0.90$ to 4.51$)$ & 0.090 \\
DM2 & $2.70(1.24$ to 5.86$)$ & 0.012 \\
RA &
\end{tabular}

DM2, diabetes mellitus type 2; RA, rheumatoid arthritis.

Model I, crude associations.

Model II, corrected for age and gender.

Model III, corrected for cardiovascular risk factors (age and gender, systolic blood pressure, antihypertensive agents, total cholesterol/high-density lipoprotein cholesterol (TC/HDL) ratio, lipid-lowering drugs, waist circumference, creatinine and smoking).

smoking) moderately attenuated the $\mathrm{OR}$ in RA, but RA remained independently associated with CVD (model III, table 2). Adding CRP to model II resulted in a slightly decreased ratio of RA to controls for CVD. For example, introduction of CRP into model II reduced the OR by approximately $5 \%$. As in some studies an ABPI cut-off value of 0.9 is used to define peripheral arterial disease, regression analyses were also performed using this cut-off value. This resulted in age- and genderadjusted OR for CVD almost 2.5 times higher than controls in DM2 and 2 times higher than controls in RA.

\section{DISCUSSION}

The risk of CVD associated with RA equals that of DM2. This excess cardiovascular risk in comparison with the general population is explained only partly by conventional cardiovascular risk factors. Hence, RA itself should be regarded as a strong independent cardiovascular risk factor for which cardiovascular risk management, as in DM2, should be considered. ${ }^{17}$

In the present study we observed a $2-3$-fold higher risk of prevalent CVD in patients with RA than in non-diabetic controls, which is similar to that in DM2. The pattern of CVD manifestations was different, however, with a predominance of coronary artery disease in RA as opposed to peripheral arterial disease in DM2. The increased CVD risk in RA could be entirely due to traditional cardiovascular risk factors, but this is unlikely. ${ }^{18-20}$ In our patients with RA, some traditional risk factors were increased, some decreased, and many were similar to controls, and these findings correspond with other studies. ${ }^{21}$ Moreover, the chance of having CVD was attenuated-but still significantly increased-after adjustment for traditional cardiovascular risk factors. Undertreatment of cardiovascular comorbidity might be another reason why patients with RA have an increased risk of CVD. ${ }^{22}$ This is also unlikely as, for instance, the ratio of subjects receiving antihypertensive agents and those who qualified for antihypertensive treatment according to national guidelines was comparable in patients with RA and controls (data not shown).

Epidemiological, clinical and laboratory investigations have shown that the immune system and inflammation play a major role in all stages of atherosclerosis and contribute considerably to the increased cardiovascular risk. ${ }^{23}$ Inflammation is known to cause deterioration of fatty streaks into (unstable) plaques, plaque ruptures and complement activation. ${ }^{24}{ }^{25}$ Inflammation may also act synergistically with conventional cardiovascular risk factors in the pathogenesis of atherosclerosis. For example, inflammation is associated with a higher systolic blood pressure and an adverse lipid profile. ${ }^{26}{ }^{27}$ Hence, it can be expected that CVD occurs more frequently in diseases with a high inflammatory burden such as RA. This is supported by observations that disease severity is associated with an increased mortality ratio, and that treatment with powerful anti-inflammatory drugs such as tumour necrosis factor $\alpha$ (TNF $\alpha)$ blocking agents reduces the cardiovascular risk in RA. ${ }^{28}{ }^{29}$ However, within the RA group as well as in the glucose-stratified participants of the Hoorn study, we were unable to demonstrate a significant relationship between inflammatory markers and CVD. This might be due to a type II error, as the study was not designed to study CVD risk at different levels of inflammation. Also, it may be that the cumulative inflammatory burden (eg, areas under the curve for CRP) over the last years would need to be assessed in order to show an association between disease activity and CVD risk in patients with RA. Indeed, in a series of 47 patients with RA without traditional cardiovascular risk factors, no correlation was found between the carotid intima media thickness (cIMT) and CRP levels at the time of ultrasound. ${ }^{30}$ However, a significant association was observed between mean CRP values and cIMT. ${ }^{31}$ The distribution of patients with RA in four quartiles according to mean CRP values revealed statistically significant differences in the cIMT. Moreover, patients with the highest mean CRP values $(>15 \mathrm{mg} / \mathrm{l}$ ) had a greater cIMT than the remaining patients.

Non-steroidal anti-inflammatory drugs (NSAIDs), cyclooxygenase-2 (COX-2) inhibitors and disease-modifying antirheumatic drugs (DMARDs) are other drugs that influence the cardiovascular risk in patients with RA. Indeed, it was shown that the use of DMARDs was associated with a lower cardiovascular risk mediated by inflammation suppression. ${ }^{32}$ The net effects of NSAIDs and COX-2 inhibitors on cardiovascular risk are more difficult to ascertain as, on the one hand, most (but not all) have prothrombotic effects and, on the other hand, these agents improve inflammation and mobility of patients with RA, which might counterbalance the prothrombotic effects. ${ }^{33}$

RA and diabetes may share several mechanisms that contribute to the increased risk of CVD, and the presence of chronic inflammation implicated in the pathogenesis of RA, diabetes and atherosclerosis appears to be the key feature. ${ }^{34} 35$ $\mathrm{TNF} \alpha$, a pivotal proinflammatory cytokine in RA, arises from adipose tissue and during chronic hyperglycaemia in DM2 and has harmful effects on the pathway of insulin signalling. ${ }^{36} \mathrm{TNF} \alpha$ may also cause insulin resistance through its ability to decrease the tyrosine kinase activity of the insulin receptor. ${ }^{37}$ In addition, TNF $\alpha$ impedes the insulin-mediated disposal of glucose in the skeletal muscle. ${ }^{38}$ Interestingly, TNF $\alpha$ blockade has been shown to yield a rapid dramatic improvement in insulin resistance in RA. $^{39} 40$ This improvement in insulin resistance following antiTNF $\alpha$ therapy has been found to yield better glycaemic control in patients with RA with concomitant diabetes. ${ }^{41}$ Glucose intolerance, present in RA and diabetes, is another parallel, and there is a direct correlation between the degree of impaired glucose handling and inflammation. ${ }^{42}$ Moreover, RA and diabetes associate with an adverse cardiovascular risk profile, particularly dyslipidaemia. ${ }^{43} 44$

Our study has several limitations. First, causality can only be investigated to a limited extent in cross-sectional epidemiological 
studies. Second, there may be differences between the Hoorn study and the CARRÉ study as cardiovascular risk measurements were performed by different physicians and some by different techniques. In particular, the different definition of diabetes in the two studies is important. In the Hoorn study, controls and DM2 were classified according to the mean of two fasting plasma glucose levels and the mean of two OGTTs, whereas one single fasting plasma glucose level was used in the CARRÉ study. Hence, the number of true non-diabetic patients in the RA group might actually be lower. Such non-exclusion of diabetic patients would inflate the OR for RA. When, however, participants of the Hoorn study were stratified according to fasting plasma glucose levels alone, the age- and gender-matched ORs for RA slightly decreased but remained more than twofold increased compared with controls in the Hoorn study (data not shown). A significant underestimation of diabetes in RA is therefore not likely. Finally, the Hoorn study was conducted about a decade earlier than the CARRÉ study. Hospital admission rates for CVD showed a marked decline during the second half of the 1990s in The Netherlands, which indicates that the prevalence of CVD in the CARRÉ study relative to the prevalence of CVD in the controls assessed one decade earlier is probably more underestimated than overestimated. ${ }^{45}$ In addition, differences in HDL-cholesterol levels between the two cohorts are difficult to interpret as HDLcholesterol levels may have drifted up over time.

In conclusion, the prevalence of CVD in RA is greatly increased compared with healthy individuals and is comparable to that in DM2. A higher prevalence of traditional cardiovascular risk factors only partly explains this increased risk of CVD in RA. Hence, RA should be considered a high-risk condition for CVD, potentially equivalent to that in DM2, emphasising the need for cardiovascular risk management in RA. Future well-controlled prospective studies including patients with RA and DM2 at baseline would be helpful to confirm and extend our findings.

\section{Competing interests: None.}

Ethics approval: The local ethics committees approved both study protocols and all participants gave their written informed consent for the studies.

\section{REFERENCES}

1. Lawrence RC, Helmick CG, Arnett FC, Deyo RA, Felson DT, Giannini EH, et al. Estimates of the prevalence of arthritis and selected musculoskeletal disorders in the United States. Arthritis Rheum 1998;41:778-99.

2. Wolfe F, Mitchell DM, Sibley JT, Fries JF, Bloch DA, Williams CA, et al. The mortality of rheumatoid arthritis. Arthritis Rheum 1994;37:481-94.

3. Van Doornum S, McColl G, Wicks IP. Accelerated atherosclerosis: an extraarticular feature of rheumatoid arthritis? Arthritis Rheum 2002;46:862-73.

4. Boers M, Dijkmans B, Gabriel S, Maradit-Kremers H, O'Dell J, Pincus T. Making an impact on mortality in rheumatoid arthritis: targeting cardiovascular comorbidity. Arthritis Rheum 2004;50:1734-9.

5. Sattar N, McCarey DW, Capell H, Mclnnes IB. Explaining how "high-grade" systemic inflammation accelerates vascular risk in rheumatoid arthritis. Circulation 2003;108:2957-63.

6. Gonzalez-Gay MA, Gonzalez-Juanatey C, Martin J. Rheumatoid arthritis: a disease associated with accelerated atherogenesis. Semin Arthritis Rheum 2005;35:8-17.

7. Haffner SM, Lehto S, Ronnemaa T, Pyorala K, Laakso M. Mortality from coronary heart disease in subjects with type 2 diabetes and in nondiabetic subjects with and without prior myocardial infarction. N Engl J Med 1998;339:229-34.

8. Arnett FC, Edworthy SM, Bloch DA, McShane DJ, Fries JF, Cooper NS, et al. The American Rheumatism Association 1987 revised criteria for the classification of rheumatoid arthritis. Arthritis Rheum 1988;31:315-24.

9. Beks PJ, Mackaay AJ, de Neeling JN, de Vries H, Bouter LM, Heine RJ. Peripheral arterial disease in relation to glycaemic level in an elderly Caucasian population: the Hoorn study. Diabetologia 1995;38:86-96.

10. Prevoo ML, 't Hof MA, Kuper HH, van Leeuwen MA, van De Putte LB, van Riel PL. Modified disease activity scores that include twenty-eight-joint counts. Development and validation in a prospective longitudinal study of patients with rheumatoid arthritis. Arthritis Rheum 1995;38:44-8.

11. Nielen MM, van Schaardenburg D, Reesink HW, van de Stadt RJ, van der HorstBruinsma IE, de Koning MH, et al. Specific autoantibodies precede the symptoms of rheumatoid arthritis: a study of serial measurements in blood donors. Arthritis Rheum 2004:50:380-6

12. Fries JF, Spitz P, Kraines RG, Holman HR. Measurement of patient outcome in arthritis. Arthritis Rheum 1980:23:137-45.

13. Alberti KG, Zimmet PZ. Definition, diagnosis and classification of diabetes mellitus and its complications. Part 1: Diagnosis and classification of diabetes mellitus provisional report of a WHO consultation. Diabet Med 1998:15:539-53.

14. Beks PJ, Mackaay AJ, de Neeling JN, de Vries H, Bouter LM, Heine RJ. Peripheral arterial disease in relation to glycaemic level in an elderly Caucasian population: the Hoorn study. Diabetologia 1995;38:86-96.

15. Hoogeveen EK, Kostense PJ, Beks PJ, Mackaay AJ, Jakobs C, Bouter LM, et al. Hyperhomocysteinemia is associated with an increased risk of cardiovascular disease, especially in non-insulin-dependent diabetes mellitus: a population-based study. Arterioscler Thromb Vasc Biol 1998;18:133-8.

16. Beks PJ, Mackaay AJ, de Neeling JN, de Vries H, Bouter LM, Heine RJ. Peripheral arterial disease in relation to glycaemic level in an elderly Caucasian population: the Hoorn study. Diabetologia 1995;38:86-96.

17. Kitas GD, Erb N. Tackling ischaemic heart disease in rheumatoid arthritis Rheumatology (Oxford) 2003;42:607-13.

18. del Rincon ID, Williams K, Stern MP, Freeman GL, Escalante A. High incidence of cardiovascular events in a rheumatoid arthritis cohort not explained by traditional cardiac risk factors. Arthritis Rheum 2001;44:2737-45.

19. Solomon DH, Karlson EW, Rimm EB, Cannuscio CC, Mandl LA, Manson JE, et al. Cardiovascular morbidity and mortality in women diagnosed with rheumatoid arthritis Circulation 2003;107:1303-7.

20. Solomon DH, Curhan GC, Rimm EB, Cannuscio CC, Karlson EW. Cardiovascular risk factors in women with and without rheumatoid arthritis. Arthritis Rheum 2004;50:3444-9.

21. Van Doornum S, McColl G, Wicks IP. Accelerated atherosclerosis: an extraarticular feature of rheumatoid arthritis? Arthritis Rheum 2002;46:862-73.

22. Boers M, Dijkmans B, Gabriel S, Maradit-Kremers H, O'Dell J, Pincus T. Making an impact on mortality in rheumatoid arthritis: targeting cardiovascular comorbidity. Arthritis Rheum 2004;50:1734-9.

23. Ross R. Atherosclerosis - an inflammatory disease. N Engl J Med 1999;340:115-26

24. Lagrand WK, Visser CA, Hermens WT, Niessen HW, Verheugt FW, Wolbink GJ, et al. C-reactive protein as a cardiovascular risk factor: more than an epiphenomenon? Circulation 1999:100:96-102.

25. Lombardo A, Biasucci LM, Lanza GA, Coli S, Silvestri P, Cianflone D, et al. Inflammation as a possible link between coronary and carotid plaque instability. Circulation 2004;109:3158-63.

26. Abramson JL, Weintraub WS, Vaccarino V. Association between pulse pressure and C reactive protein among apparently healthy US adults. Hypertension 2002:39:197-202

27. Peters MJ, Vis M, van Halm VP, Wolbink GJ, Voskuyl AE, Lems WF, et al. Changes in lipid profile during infliximab treatment and corticosteroid therapy in rheumatoid arthritis. Ann Rheum Dis 2007:66:958-61.

28. Jacobsson LT, Turesson C, Gulfe A, Kapetanovic MC, Petersson IF, Saxne T, et al. Treatment with tumor necrosis factor blockers is associated with a lower incidence of first cardiovascular events in patients with rheumatoid arthritis. J Rheumatol 2005; 32:1213-8.

29. Maradit-Kremers H, Nicola PJ, Crowson CS, Ballman KV, Gabriel SE. Cardiovascular death in rheumatoid arthritis: a population-based study. Arthritis Rheum 2005;52:722-32.

30. Gonzalez-Juanatey C, Llorca J, Testa A, Revuelta J, Garcia-Porrua C, Gonzalez-Gay MA. Increased prevalence of severe subclinical atherosclerotic findings in long-term treated rheumatoid arthritis patients without clinically evident atherosclerotic disease. Medicine (Baltimore) 2003;82:407-13.

31. Gonzalez-Gay MA, Gonzalez-Juanatey C, Pineiro A, Garcia-Porrua C, Testa A, Llorca $J$. High-grade $\mathrm{C}$-reactive protein elevation correlates with accelerated atherogenesis in patients with rheumatoid arthritis. J Rheumatol 2005;32:1219-23.

32. van Halm VP, Nurmohamed MT, Twisk JW, Dijkmans BA, Voskuyl AE. Diseasemodifying antirheumatic drugs are associated with a reduced risk for cardiovascular disease in patients with rheumatoid arthritis: a case control study. Arthritis Res Ther 2006:8:R151.

33. Kearney PM, Baigent C, Godwin J, Halls H, Emberson JR, Patrono C. Do selective cyclo-oxygenase- 2 inhibitors and traditional non-steroidal anti-inflammatory drugs increase the risk of atherothrombosis? Meta-analysis of randomised trials. BMJ 2006;332:1302-8.

34. Mazzone T, Chait A, Plutzky J. Cardiovascular disease risk in type 2 diabetes mellitus: insights from mechanistic studies. Lancet 2008:371:1800-9.

35. Sattar N, McCarey DW, Capell H, McInnes IB. Explaining how "high-grade" systemic inflammation accelerates vascular risk in rheumatoid arthritis. Circulation 2003; 108:2957-63.

36. Fukuzawa M, Satoh J, Qiang X, Miyaguchi S, Sakata Y, Nakazawa T, et al. Inhibition of tumor necrosis factor-alpha with anti-diabetic agents. Diabetes Res Clin Pract 1999:43:147-54.

37. Hotamisligil GS, Peraldi P, Budavari A, Ellis R, White MF, Spiegelman BM. IRS-1 mediated inhibition of insulin receptor tyrosine kinase activity in TNF-alpha- and obesity-induced insulin resistance. Science 1996;271:665-8.

38. Eringa EC, Stehouwer CD, Walburg K, Clark AD, van Nieuw Amerongen GP, Westerhof $\mathrm{N}$, et al. Physiological concentrations of insulin induce endothelindependent vasoconstriction of skeletal muscle resistance arteries in the presence of tumor necrosis factor-alpha dependence on c-Jun N-terminal kinase. Arterioscler Thromb Vasc Biol 2006:26:274-80. 
39. Gonzalez-Gay MA, De Matias JM, Gonzalez-Juanatey C, Garcia-Porrua C, Sanchez-Andrade A, Martin J, et al. Anti-tumor necrosis factor-alpha blockade improves insulin resistance in patients with rheumatoid arthritis. Clin Exp Rheumatol 2006;24:83-6.

40. Kiortsis DN, Mavridis AK, Vasakos S, Nikas SN, Drosos AA. Effects of infliximab treatment on insulin resistance in patients with rheumatoid arthritis and ankylosing spondylitis. Ann Rheum Dis 2005;64:765-6.

41. van Eijk IC, Peters MJ, Nurmohamed MT, van Deutekom AW, Dijkmans BA, Simsek $S$. Decrease of fructosamine levels during treatment with adalimumab in patients with both diabetes and rheumatoid arthritis. Eur J Endocrinol 2007;156:291-3.
42. Dessein PH, Joffe BI, Stanwix A, Botha AS, Moomal Z. The acute phase response does not fully predict the presence of insulin resistance and dyslipidemia in inflammatory arthritis. J Rheumatol 2002;29:462-6.

43. Steiner G, Urowitz MB. Lipid profiles in patients with rheumatoid arthritis: mechanisms and the impact of treatment. Semin Arthritis Rheum 2009;38: 372-81.

44. Chahil TJ, Ginsberg HN. Diabetic dyslipidemia. Endocrinol Metab Clin North Am 2006;35:491-viii.

45. Koek HL, Grobbee DE, Bots ML. [Trends in cardiovascular morbidity and mortality in the Netherlands, 1980-2000]. Ned Tijdschr Geneeskd 2004;148:27-32. 